\title{
Statural and Weight Growth of Low Birth Weight at 9 Months
}

\section{Modou Gueye ${ }^{1}$, Amadou Sow1, Djibril Boiro'1, Youssouf Mmadi Ibrahim1, Aissatou Cisse Bathily1, Benjeloun Amane1, Assane Sylla², Papa Moctar Faye3, Ousmane Ndiaye ${ }^{3}$}

\author{
${ }^{1}$ Abass Ndao Hospital Center, Dakar, Senegal \\ ${ }^{2}$ Aristide le Dantec Hospital Center, Dakar, Senegal \\ ${ }^{3}$ Albert Royer National Hospital Center, Fann, Dakar, Senegal \\ Email: *modougueye2009@gmail.com
}

How to cite this paper: Gueye, M., Sow, A., Boiro, D., Ibrahim, Y.M., Bathily, A.C., Amane, B., Sylla, A., Faye, P.M. and Ndiaye, O. (2022) Statural and Weight Growth of Low Birth Weight at 9 Months. Open Journal of Pediatrics, 12, 19-25.

https://doi.org/10.4236/ojped.2022.121003

Received: November 27, 2021

Accepted: January 11, 2022

Published: January 14, 2022

Copyright $\odot 2022$ by author(s) and Scientific Research Publishing Inc. This work is licensed under the Creative Commons Attribution International License (CC BY 4.0).

http://creativecommons.org/licenses/by/4.0/

\section{Open Access}

\begin{abstract}
Introduction: Low birth weight (LBW) is defined as a birth weight $<2500 \mathrm{~g}$ at birth, regardless of the term of pregnancy. The objective of this study is to evaluate their stature and weight growth from 0 to 9 months of corrected age (CA) in Senegal. Methodology: This is a prospective, descriptive, and analytical cohort follow-up up to 9 months of CA including all live newborns of LBW hospitalized and followed up from 01 August 2019 to 31 May 2020. World Health Organization growth charts were used to assess stature and weight growth. Results: During the study 136 LBW newborns were included. The mean gestational age was 32 weeks of amenorrhea. At discharge, 46 children (33.82\%) were exclusively breastfed. At birth, the mean weight was $1487 \mathrm{~g}\left(3^{\text {rd }}-10^{\text {th }}\right.$ percentile $)$ and the mean height was $41.52 \mathrm{~cm}\left(10^{\text {th }}-25^{\text {th }}\right.$ percentile). At 9 months of CA, the mean weight was $8119 \mathrm{~g}$ (median) and the mean height was $74 \mathrm{~cm}$ (median). The children had achieved satisfactory growth in weight (84\%) and height (89\%). At 9 months of CA, $27 \%$ of the children were behind in one of the four areas of psychomotor development. Conclusion: At the end of 9 months of CA, stature and weighted growth was normal.
\end{abstract}

\section{Keywords}

Low-Birth-Weight, Growth, Stature, Weight, Child, Senegal

\section{Introduction}

Low birth weight (LBW) is defined as any live birth with a weight $<2500$ g, regardless of the term of the pregnancy [1]. In sub-Saharan Africa, one in 36 
children dies in the first month of life, compared to one in 333 in developed countries [2]. In Senegal, neonatal mortality was estimated at 23 per thousand in 2018, representing almost half of infant and child mortality [3]. The main causes of neonatal deaths worldwide are low birth weight (prematurity and intrauterine growth retardation) followed by infection and perinatal asphyxia [2] [4]. Globally, about 20 million children are born weighing less than $2500 \mathrm{~g}$ and more than $96 \%$ of them are born in developing countries [5]. In addition to high mortality, LBW can affect psychomotor development and subsequent growth [6] [7]. The aim of this study was to analyze the impact of the LBW anomaly on the short-term outcome, in particular on the stature and weight development of these children from birth to the corrected age of 9 months.

\section{Methodology}

This is a prospective, descriptive and analytical study conducted from 01 August 2019 to 31 May 2020 (10 months). It was carried out in the hospital environment in the neonatology unit of the Abass Ndao University Hospital of Dakar, which is a level 3 hospital in the national health pyramid. This center houses one of the largest mother-child centers in the country with a large maternity ward with a capacity of more than 5000 deliveries per year. In addition to the maternity ward, the neonatology department is also a referral service that receives newborns from all regions of the country. The study included all live newborns weighing less than $2500 \mathrm{~g}$ at birth admitted during the study period. The data were collected from the pre-established forms (Appendix) based on the records of the hospitalized newborns and during the follow-up in the service. The newborns were followed up with scheduled visits at 40 days' gestation and at corrected age (CA) of 2 months, 4 months, 6 months, and 9 months. During each visit, the following data were collected anthropometric data (weight, height, head circumference, Lefort-Leroy growth curves and WHO standard growth curves). The data were recorded on a computerized survey form using Sphinx software version 5.1.0.7. Data analysis was performed with SPSS version 18.0. The descriptive study was carried out with the calculation of frequency and proportion for the qualitative variables and the calculation of means for the quantitative variables. The analytical study was done with cross-tabulations.

\section{Results}

\subsection{Socio-Demographic Data}

During the study period, 556 LBW newborns were admitted out of a total of 1414 newborns, i.e. 39.32\% of newborns. Among the LBWs, 98 died during hospitalization (17.62\%), 19 were referred to other health facilities and 322 (57.9\%) were lost to follow-up. Thus, we collected 136 LBW newborns, $82 \%$ of whom were born in the hospital maternity ward (in-Born). The level of education was low, with only $29.41 \%$ having attained higher education, despite a high school enrolment rate $(88.97 \%)$. 


\subsection{Maternal and Neonatal Data}

The average age of the mothers was 27.53 years [extremes 15 and 44 years] with a peak in frequency between 18 and 34 years, representing $72.8 \%$ of the mothers. During pregnancy, 64 (47\%) of the women had presented an obstetric complication and pre-eclampsia was the most frequent with $21.32 \%$. The mean gestational age was 32.07 days after birth. In our population, 71 newborns (52.2\%) were very premature at less than 32 weeks of amenorrhea. The sex ratio was 1.1. The birth weight was between 1500 - 2499 for 66 newborns (48.53\%) with a mean birth weight of $1487 \mathrm{~g}$ [extremes $750-2400 \mathrm{~g}$ ]. The mean height at birth was $41.52 \mathrm{~cm}$, between the $10^{\text {th }}$ and $25^{\text {th }}$ percentile [extremes 33 and $48 \mathrm{~cm}$ ] and 19 babies (14\%) had a height at age below the $3^{\text {rd }}$ percentile. The mean head circumference $(\mathrm{HC})$ at birth was $30.47 \mathrm{~cm}$ at the $50^{\text {th }}$ percentile and $22(16.17 \%)$ had a $\mathrm{HC}$ at age below the $3^{\text {rd }}$ percentile. Intrauterine growth retardation was present in $60 \%$ of cases. Respiratory distress and hypothermia were the main neonatal complications with $74.26 \%$ and $68.38 \%$ respectively. The average length of hospitalization was 11.84 days [extremes 2 and 66 days]. Anthropometric parameters at birth are summarized in Table 1 .

\subsection{Data on Feeding Mode}

In hospital all newborns were on mixed feeding and 103 (75.73\%) newborns were on parenteral feeding. At discharge, 79 newborns (58\%) remained on the mixed diet. Almost all the children (92\%) were breastfed. However, only $33.82 \%$ of the children under six months of age were exclusively breastfed.

\section{Evolution of Anthropometric Data during Follow-Up}

- At discharge: The mean post-conceptional age at discharge was 35SA. The mean weight at discharge was $1703 \mathrm{~g}$ and 86 newborns (63.23\%) had a weight for age below the $3^{\text {rd }}$ percentile. The mean height at discharge was $43.67 \mathrm{~cm}$, between the $3^{\text {rd }}$ and $10^{\text {th }}$ percentile, and 62 babies $(45.6 \%)$ had a height-forage below the $3^{\text {rd }}$ percentile. The mean head circumference at discharge was $31.25 \mathrm{~cm}$ between the $25^{\text {th }}$ and $50^{\text {th }}$ percentile and 36 newborns $(26.47 \%)$ had an age-related $\mathrm{HC}$ below the $3^{\text {rd }}$ percentile.

- At 40 weeks post-conceptional: The mean weight was $2639.27 \mathrm{~g}$ and 49 children $(36.03 \%)$ had a weight for age below the $3^{\text {rd }}$ percentile. The mean

Table 1. Distribution according to average anthropometric parameters at birth (LefortLeroy curve).

\begin{tabular}{ccc}
\hline Repartition & Medium & percentile \\
\hline Gestational Age & $32.07 \mathrm{SA}$ & \\
Weight & $1487.61 \mathrm{~g}$ & $<10$ \\
Length & $41.52 \mathrm{~cm}$ & $>10$ \\
Head Circumference & $30.47 \mathrm{~cm}$ & $>10$ \\
\hline
\end{tabular}


height was $49.67 \mathrm{~cm}$, between the $25^{\text {th }}$ and $50^{\text {th }}$ percentile and 26 children (19.12\%) were below the $3^{\text {rd }}$ percentile for height for age. The mean head circumference was $34.7 \mathrm{~cm}$ between the $25^{\text {th }}$ and $50^{\text {th }}$ percentiles and 6 children $(4.41 \%)$ had a $\mathrm{HC}$ for age below the $3^{\text {rd }}$ percentile

- At 2 months corrected age (CA): The mean weight was $4666.76 \mathrm{~g}$ (between the $15^{\text {th }}$ and $50^{\text {th }}$ percentile) and 27 children (or $19.85 \%$ ) had a weight for age below the $3^{\text {rd }}$ percentile. The mean height was $56.7 \mathrm{~cm}\left(15^{\text {th }}\right.$ percentile $)$ and 29 children $(21.32 \%)$ had a height-for-age below the $3^{\text {rd }}$ percentile. The mean head circumference was $39.07 \mathrm{~cm}$ ( $50^{\text {th }}$ percentile) and 26 children (or 19.12\%) had a $\mathrm{HC}$ for age below the $3^{\text {rd }}$ percentile.

- At 6 months of CA: The mean weight was $7532.35 \mathrm{~g}$ (between the $50^{\text {th }}$ and $85^{\text {th }}$ percentile) and 11 children $(8.1 \%)$ were below the $3^{\text {rd }}$ percentile for weight for age. The mean height was $71.27 \mathrm{~cm}$ (between the $85^{\text {th }}$ and $97^{\text {th }}$ percentile) and 7 children $(5.14 \%)$ had a height at age below the $3^{\text {rd }}$ percentile. The mean head circumference was $45.94 \mathrm{~cm}$ (between the $85^{\text {th }}$ and $97^{\text {th }}$ percentile) and 5 children (3.67\%) had a $\mathrm{HC}$ relative to age below the $3^{\text {rd }}$ percentile

- At 9 months of CA: The mean weight was $8119.26 \mathrm{~g}$ (between the $15^{\text {th }}$ and $50^{\text {th }}$ percentile) and 5 children (3.67\%) were below the $3^{\text {rd }}$ percentile weight for age. The mean height was $74.3 \mathrm{~cm}$ (between the $50^{\text {th }}$ and $85^{\text {th }}$ percentile) and 4 children (2.94\%) had a height at age below the $3^{\text {rd }}$ percentile. The mean head circumference was $46.6 \mathrm{~cm}$ (between the $85^{\text {th }}$ and $97^{\text {th }}$ percentile) and 3 children (or 2.2\%) had a $\mathrm{HC}$ for age below the $3^{\text {rd }}$ percentile.

- In total: The average weight gain from corrected PCA to 9 months corrected age was 1326.33 gr. The mean stature gain from corrected PCA to 9 months corrected age was $6.5 \mathrm{~cm}$. The average gain in CP between the corrected APC and 9 months of corrected age was $3.2 \mathrm{~cm}$. The evolution of the curves of the different growth parameters are summarized in Figure 1 and Figure 2.

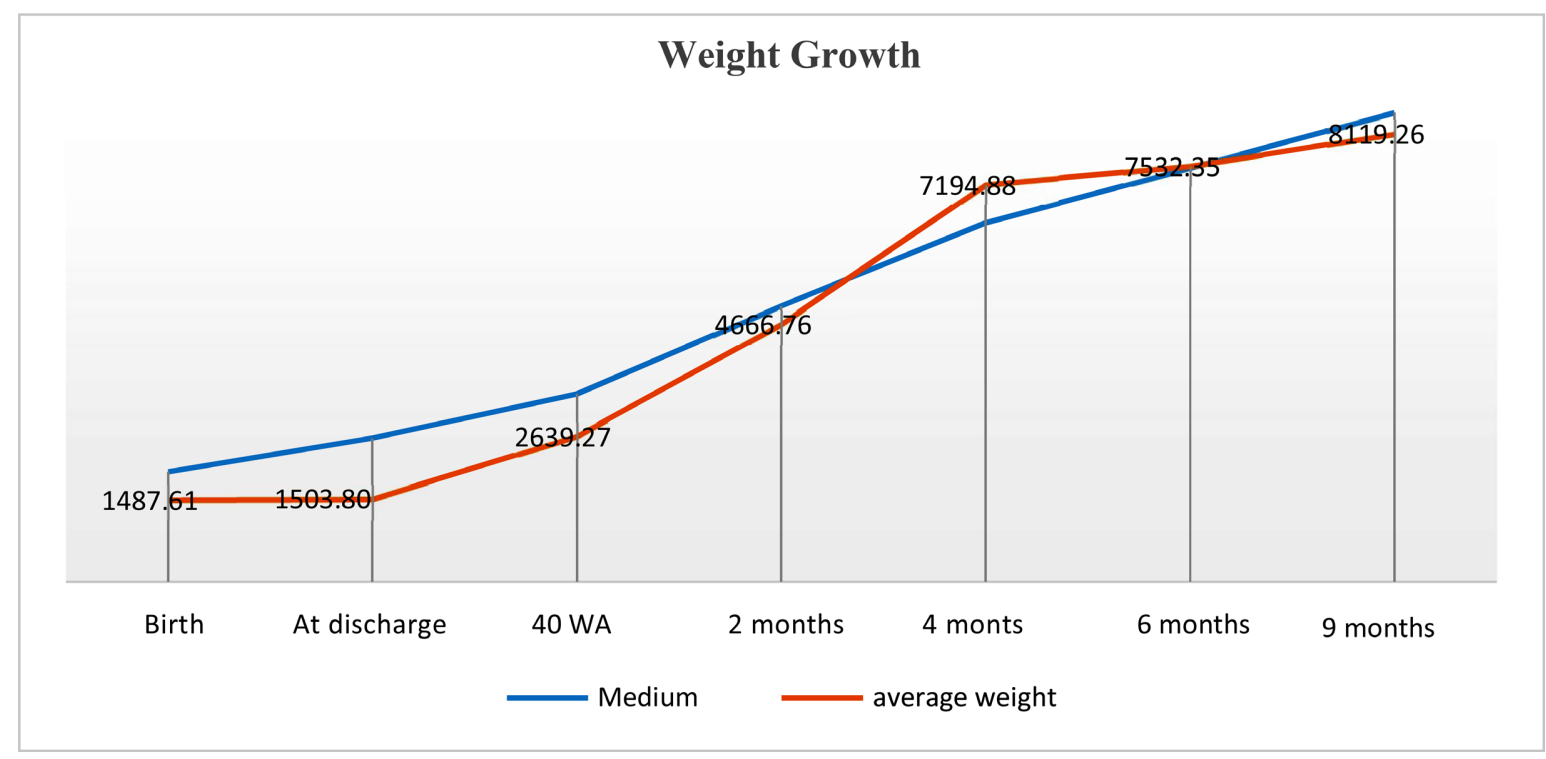

Figure 1. Distribution by weight growth. 


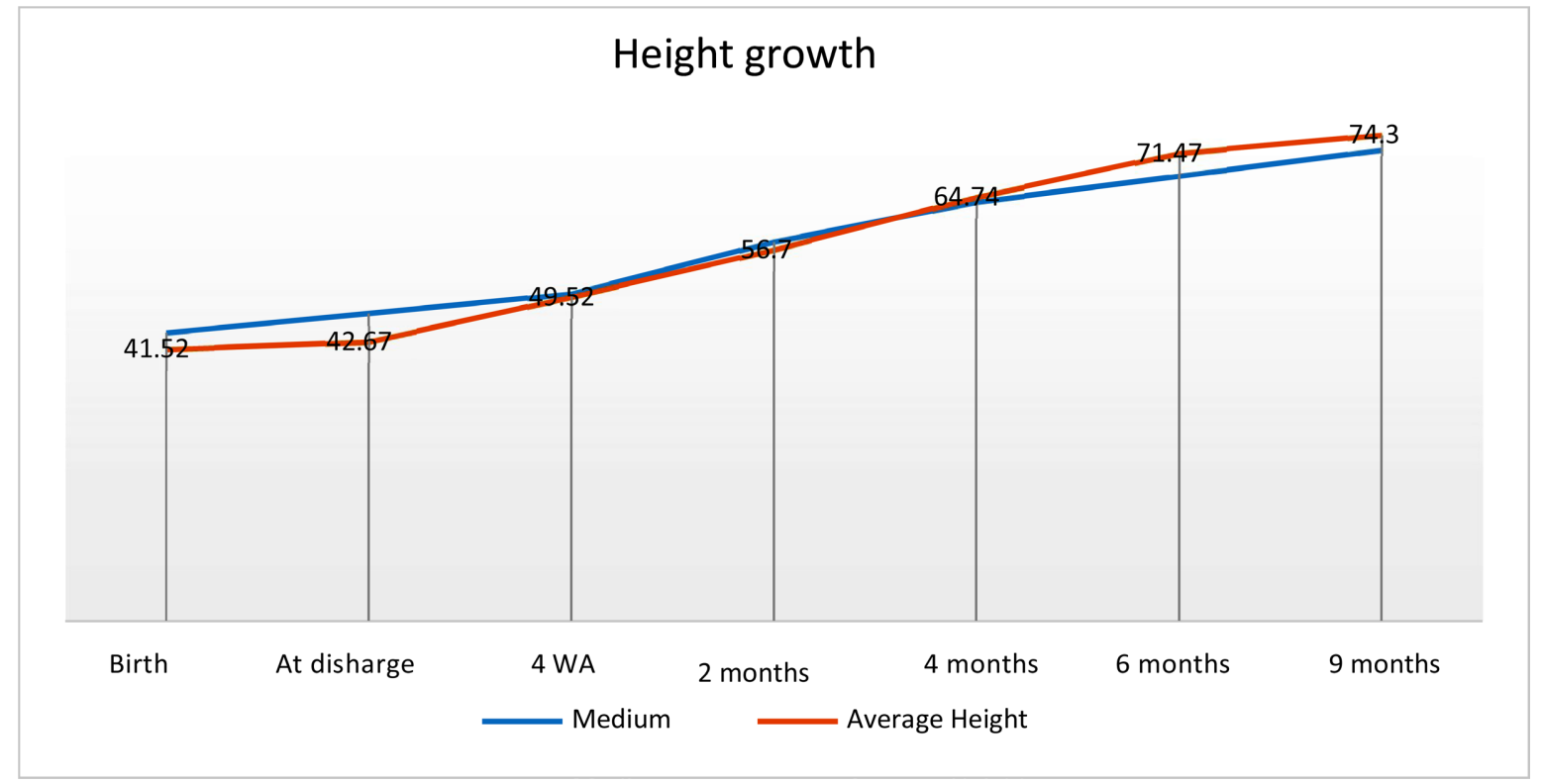

Figure 2. Distribution of patients by height growth.

\section{Discussion}

\subsection{Socio-Demographic Aspects}

The prevalence of LBW was $39.32 \%$. This prevalence was higher than those reported by UNICEF worldwide (15.5\%), in Africa (14.3\%) and particularly in West Africa 15.4\% [8]. In Senegal in 2018 the prevalence was 12\% [3]. In underdeveloped countries, LBW occurs mainly because of poor fetal growth, as confirmed again by Sania et al. in Tanzania [9] [10]. Loss of sight represents more than $50 \%$ of the initial population. The high number of drop-outs could be explained by the remoteness of these children's homes, the low socio-economic level and the health context related to the Covid-19 pandemic. In our study, we found that the frequency of LBW was higher in the 18 - 34 age group, i.e. $72.8 \%$, and the average age of mothers was 27.53 years. These results are comparable to those of Charpak N et al. [2], Kabore et al. [11] and Luhete P K et al. [13], i.e. 27.3 years, 29.7 years and 26.6 years respectively. It is classically reported that primiparity, the age of the mothers, lack of employment, and low level of education increase the birth of premature babies or LBW [14] [15] [16].

\subsection{Weight Growth}

At term (40 SA post-conception), the mean weight was $2639 \mathrm{~g}$, the mean height was $49.67 \mathrm{~cm}$ and the mean head circumference was $34.7 \mathrm{~cm}$ with $36 \%$ of the population underweight at the $3^{\text {rd }}$ percentile. This was slightly lower than the average weight in Bogota (2851 g) [2] and Vietnam (2920 g) [9]. At 9 months corrected age, the mean weight was $8119.26 \mathrm{~g}$, the mean height was $74.3 \mathrm{~cm}$ and the mean head circumference was $46.6 \mathrm{~cm}$. The weight growth of the LBW children remained below -2 DS for $16.17 \%$ of whom only $3.67 \%$ were below -3 DS. This means that in our series, most children (84\%) were able to achieve 
satisfactory weight gain at 9 months. Other studies have shown the same tendency for weight gain in LBW in the first year. The study by Gascoin G et al. on the evaluation of the long-term consequences of children born in the context of LBW found that most children had caught up in weight by 6 months [1] [17].

\subsection{Stature Growth}

The dynamics of stature catching up in our series was more important with a better progression up to almost $90 \%$ at 9 months. Only $11 \%$ of the children had a height at 9 months lower than -2DS and 4 children (3\%) had a height for age lower than -3DS. Other studies have confirmed that the majority of children have caught up in height in the first 2 years and that there is very little catching up after 2 years. Studies have shown stature recovery in the first 6 months, and at 1 year of age only $13.4 \%$ of LBW infants were below -2DS [18] [19]. However, genetic factors, including parental height, should not be overlooked in the growth potential of the child in height.

\subsection{Growth in Head Circumference (HC)}

The head circumference of the children remained below -2DS at 9 months in $6 \%$ and 7 children $(5.14 \%)$ had a HC for age below -3DS. Failure to catch up in HC growth at one year is still considered to be a poor prognosis [18]. Brandt et al. described the more frequent occurrence of cognitive impairment when head circumference was less than -2DS between 12 and 18 months corrected age [19].

\section{Conclusion}

At the end of 9 months of CA, stature and weighted growth was normal.

\section{Conflicts of Interest}

The authors declare no conflicts of interest regarding the publication of this paper.

\section{References}

[1] Albertsson-Wikland, K. and Karlberg, J. (1997) Postnatal Growth of Children Born Small for Gestational Age. Acta Paediatrica, 423, 193-195. https://doi.org/10.1111/j.1651-2227.1997.tb18413.x

[2] Charpak, N., Ruiz Pelaez, J.G., Figueroa De Calume, Z. and Charpak, Y. (1997) Kangaroo Mother versus Traditional Care for Newborn Infants $\leq 2000$ Grams: A Randomised Controlled Trial. Pediatrics, 100, 682-688. https://doi.org/10.1542/peds.100.4.682

[3] Sénégal (2018) Enquête Démographique et De Santé Continue.

[4] Charpak, N., Ruiz-Pelaez, J.G., Zita Figueroa de, C., et al. (2001) A Randomized, Controlled Trial of Kangaroo Mother Care: Results of Follow-Up at 1 Year of Corrected Age. Pediatrics, 108, 1072-1079. https://doi.org/10.1542/peds.108.5.1072

[5] Charpak, N., Ruiz-Peláez, J.G. and Charpak, Y. (1994) Rey-Martinez Kangaroo Mother Program: An Alternative Way of Carin for Low Birth Weight Infants? One Year Mortality in a Two Cohort Study. Pediatrics, 94, 804-810. https://doi.org/10.1542/peds.94.6.804 
[6] Conseil Général de la Creuse (2020) Etat de santé de la petite enfance en creuse. Exploitation des certificats de santé du 9ème mois.

[7] Diouf, F.N., Diallo, F.B. and Thiam, L. (2017) Evaluation de la prématurité supérieure ou égale à $32 \mathrm{SA}$ à l'hôpital régional de Ziguinchor au Sud du Sénégal. European Scientific Journal, 13, 325-339. https://doi.org/10.1016/j.nephro.2017.08.219

[8] WHO/UNICEF (2004) Low Birth Weight. Country Regional and Global Estimates. UNICEF, New York.

[9] Gascoin, G. and Flamant, C. (2013) Conséquences à long terme des enfants nés dans un contexte de retard de croissance intra-utérin et/ou petits pour l'âge gestationnel. Journal de Gynécologie Obstétrique et Biologie de la Reproduction, 42, 911-920. https://doi.org/10.1016/j.jgyn.2013.09.014

[10] Goto, M.M.F., Gonçalves, V.M.G., Netto, A.A., et al. (2005) Neurodevelopment of Full-Term Small for Gestational Age Infants in the Second Month of Life. Arquivos de Neuro-Psiquiatria, 63, 75-82. https://doi.org/10.1590/S0004-282X2005000100014

[11] Kabore, P., Donnen, P. and Dramaix, M. (2007) Facteurs de risque obstétricaux du petit poids de naissance à terme en milieu rural sahélien. Santé Publique, 19, 489497. https://doi.org/10.3917/spub.076.0489

[12] Luhete, P.K., Mukuku, O. and Muenze Kayamba, P.K. (2015) Etude du faible poids de naissance associé à l'âge maternel et la parité dans une population couple mèreenfant suivi à Lubumbashi. The Pan African Medical Journal, 20, Article No. 246. https://doi.org/10.11604/pamj.2015.20.246.5169

[13] Balaka, B., Baeta, S., Agbèrè, A.D., Boko, K., Kessie, K., et al. (2002) Facteurs de risque associés à la prématurité au CHU de lomé, Togo. Bulletin de la Société de Pathologie Exotique, 95, 280-283.

[14] Ndiaye, O., Fall, A.L., Gueye Ba, M., Gueye, A.M., et al. (2006) Facteurs de risqué associés au petit poids de naissance: A propos d'une étude cas-témoin à la maternité du centre hospitalier de Thiès (Sénégal). Journal de Pédiatrie et de Puériculture, 19, 153-158. https://doi.org/10.1016/j.jpp.2006.03.003

[15] Nzaji, M.K., Museka, J.K. and Kangulu, I.B. (2014) Influence de l'Age et de la Parité de la Mère sur le Poids de Naissance (Cas du Centre de Santé Shungu en RDC). Health Sciences and Disease, 15, 1-4.

[16] Lundington Hoes, S.M., Nguyen, N., Swinth, J.Y., et al. (2000) Kangaroo Care Compared to Incubators in Maintaining Body Warmth in Preterm Infants. Biological Research for Nursing, 2, 60-73. https://doi.org/10.1177/109980040000200107

[17] Lee, P.A., Chernausek, S.D., Hokken-Koelega, A.C., et al. (2003) International Small for Gestational Age Advisory Board Consensus Development Conference Statement: Management of Short Children Born Small for Gestational Age, April 24-October 1, 2001. Pediatrics, 111, 1253-1261. https://doi.org/10.1542/peds.111.6.1253

[18] Karlberg, J. and Albertsson-Wikland, K. (1995) Growth in Full-Term Small-forGestational-Age Infants: From Birth to Final Height. Pediatric Research, 38, 733-739. https://doi.org/10.1203/00006450-199511000-00017

[19] Brandt, I., Sticker, E.J. and Lentze, M.J. (2003) Catch-Up Growth of Head Circumference of Very Low Birth Weight, Small for Gestational Age Preterm Infants and Mental Development to Adulthood. The Journal of Pediatrics, 142, 463-468. https://doi.org/10.1067/mpd.2003.149 